\title{
Correction to: Differences in bone quality and strength between Asian and Caucasian young men
}

\author{
A. L. Kepley ${ }^{1} \cdot$ K. K. Nishiyama ${ }^{1}$ • B. Zhou ${ }^{3} \cdot$ J. Wang $^{3} \cdot$ C. Zhang $^{1} \cdot$ D. J. McMahon ${ }^{1} \cdot$ K. F. Foley ${ }^{1}$ - M. D. Walker ${ }^{1}$. \\ X. E. Guo ${ }^{3} \cdot$ E. Shane $^{1} \cdot$ T. L. Nickolas ${ }^{2}$
}

Published online: 28 August 2018

(C) International Osteoporosis Foundation and National Osteoporosis Foundation 2018

\section{Correction to: Osteoporos Int \\ https://doi.org/10.1007/s00198-016-3762-9}

The second name of the ninth author, X.E. Guo, was incorrectly coded as part of his surname. The publisher apologises for the inconvenience caused.

The online version of the original article can be found at https://doi.org/ 10.1007/s00198-016-3762-9

T. L. Nickolas

tln2001@cumc.columbia.edu

1 Department of Medicine, Endocrinology, Columbia University Medical Center, New York, NY, USA

2 Department of Medicine, Nephrology, Columbia University Medical Center, 622 West 168th Street, PH4-124, New York, NY 10032, USA

3 Biomedical Engineering, Department of Medicine, Columbia University, New York, NY, USA 